\title{
Commentary \\ Cortactin overexpression results in sustained epidermal growth factor receptor signaling by preventing ligand-induced receptor degradation in human carcinoma cells
}

\author{
1Department of Pathology, Leiden University Medical Center, Leiden, The Netherlands \\ 2Department of Pathology, University Medical Center Groningen, The Netherlands
}

Agnes GSH van Rossum ${ }^{1}$, Johan Gibcus ${ }^{2}$, Jacqueline van der Wal2 and Ed Schuuring ${ }^{2}$

Corresponding author: Ed Schuuring, e.schuuring@path.umcg.nl

Published: 25 August 2005

This article is online at http://breast-cancer-research.com/content/7/6/235

(c) 2005 BioMed Central Ltd

Breast Cancer Research 2005, 7:235-237 (DOI 10.1186/bcr1316)

\begin{abstract}
The chromosome 11 q13 region is frequently amplified in human carcinomas and results in an increased expression of various genes including cortactin, and is also associated with an increased invasive potential. Cortactin acts as an important regulator of the actin cytoskeleton. It is therefore very tempting to speculate that cortactin is the crucial gene within the $11 \mathrm{q} 13$ amplicon that mediates the invasive potential of these carcinomas. Cortactin also participates in receptor-mediated endocytosis, and recent findings have shown that, during receptor internalization, cortactin overexpression inhibits the ubiquitylation-mediated degradation of the epidermal growth factor receptor, resulting in a sustained ligand-induced epidermal growth factor receptor activity.
\end{abstract}

Cell structure is maintained by the combined action of microtubules, intermediate filaments and the actin cytoskeleton. Actin filaments contribute to alterations in the cell shape, motility, adhesion, polarization, contraction, cytokinesis, signal transduction, endocytosis and intracellular vesicle trafficking. Cortactin [1], as a regulator of actin cytoskeleton organization, is involved in many of these processes (reviewed in $[2,3]$ ). For instance, many observations revealed that cells overexpressing cortactin show enhanced cell migration, invasion and increased metastatic potential in vivo [4-6]. Furthermore, downregulation of cortactin in highly invasive cells in vitro using small RNA interference (van Rossum, Moolenaar, Schuuring, unpublished research), deletion mutants or microinjection of antibodies resulted in a decreased invasive potential $[4,6,7]$.

Interestingly, human cortactin was identified as one of the overexpressed genes within the amplified chromosome $11 q 13$ region $[8,9]$. The $11 q 13$ region is frequently amplified in human malignancies such as breast carcinomas (13\%) and head/neck carcinomas (36\%) [10,11]. In these patients, both 11 q13 amplification and cortactin overexpression correlate with markers indicative of poor prognosis, such as the presence of lymph node metastases [10-12]. Because cortactin acts as a regulator of the actin cytoskeleton integrity, it is tempting to speculate that cortactin mediates the invasive and metastatic potential of carcinomas with 11 q13 amplification.

With the identification of the growing number of cortactininteracting proteins, novel functions of cortactin have emerged [2,13]. Cortactin has been implicated in endocytosis by its localization in endosomal vesicles [14]. Furthermore, GTPase dynamin-2 was identified as a cortactininteracting protein and, as such, linked the actin cytoskeleton to clathrin-dependent endocytosis [15]. More recent studies [16-18] provide convincing evidence that cortactin is involved in dynamin-mediated, clathrin-dependent endocytosis. Many growth factor receptors, including epidermal growth factor receptor (EGFR), are regulated via this classic endocytic pathway (reviewed in $[19,20]$ ). The ligand-induced EGFR is trapped on the plasma membrane into clathrin-coated pits, which is followed by the formation of clathrin-coated vesicles by dynamin-mediated fission and fusion. These vesicles form early endosomes that can mature towards late lysosomal endosomes. Under certain circumstances, however, the EGFR might be prevented from entering the lysosomal endosome and may become recycled to the cell surface, a mechanism that fine-tunes the activity of the EGFR [19].

It was recently demonstrated that ubiquitylation by $\mathrm{Cbl}$ triggers the EGFR to enter lysosomal endosomes, resulting in its degradation (reviewed by [20]). For instance, the EGFR with mutations at the Cbl-docking site will not be degraded and is recycled back to the plasma membrane. Other members of the ErbB-family, such as ErbB2, that lack a docking site for $\mathrm{Cbl}$, can form heterodimers with the EGFR. 
This thereby reduces the ability of the EGFR to associate with $\mathrm{Cbl}$, resulting in an increased recycling of the receptor. Finally, EGFRvIll, a mutant found in glioblastoma that lacks a portion of the extracellular domain, showed defects in internalization and ubiquitylation by $\mathrm{Cbl}$.

Timpson and colleagues hypothesized in an earlier issue of Cancer Research that cortactin is also involved in modulating EGFR activity [21]. They showed that the EGFR is degraded less efficiently in cells with increased cortactin expression, and that the EGFR activity upon ligand stimulation is sustained. In agreement with these experiments, expression of cortactin correlated well with ligand-stimulated EGFR signal transduction in cell lines derived from head/neck carcinomas. In addition, increased expression levels of cortactin did not significantly influence EGFR internalization, but resulted in accelerated recycling - leading the authors to speculate that cortactin might have an effect on the transfer of the EGFR from the early to the late lysosomal endosomes. Indeed, the EGFR was not efficiently ubiquitylated in cells that overexpressed cortactin, resulting in inhibition of the ligand-induced downregulation of the receptor and sustained epidermal growth factor-induced Erk activity. The decrease in ubiquitylation was accompanied by the inhibition of $\mathrm{Cbl}$ binding to the EGFR.

The mechanism for the observed effects of cortactin overexpression on $\mathrm{Cbl}$ function is presently unclear. The authors discuss several possibilities to explain the impaired Cbl activity [21]. Activated Cdc42 binds to Cbl via p85Cool-1/ $\beta-P i x$ and prevents $\mathrm{Cbl}$ interacting with the EGFR, thus preventing receptor ubiquitylation [22]. Fgd1, a Cdc42 guanine nucleotide exchange factor, was recently identified to interact with cortactin [23]. Overexpression of cortactin might therefore activate Cdc42 via Fgd1, leading to Cdc42/p85Cool-1/ $\beta$ $\mathrm{Pix} / \mathrm{Cbl}$ complex formation and consequently reducing the interaction of Cbl to the EGFR. Timpson and colleagues [21] demonstrated that $\mathrm{Cbl}$ tyrosine phosphorylation as well its interaction with the EGFR was reduced in cortactinoverexpressing cells, whereas the amount of $\mathrm{Cbl}$ was not affected. Cbl is a substrate for nonreceptor tyrosine kinase Src, and phosphorylation of $\mathrm{Cbl}$ is necessary to activate its ubiquitin ligase activity [24]. Overexpression of cortactin, one of the most prominent substrates for Src, might therefore sequester Src from $\mathrm{Cbl}$ to prevent $\mathrm{Cbl}$ phosphorylation and thereby prevent its ability to ubiquitylate the EGFR. Finally, cortactin overexpression did not cause EGFR internalization, but after 60-120 min of epidermal growth factor stimulation the EGFR reappeared on the cell surface. At the same time, degradation of the EGFR was also observed in cortactinoverexpressing cells. Since no degradation of the EGFR was observed until 30 min of epidermal growth factor stimulation in these cells, the enhancement of Erk activation after 5-10 min of epidermal growth factor stimulation suggests an altered trafficking between specific endosomal compartments [21]. However, it is not known exactly how cortactin affects EGFR trafficking.
In conclusion, it is presently unclear how cortactin overexpression impairs $\mathrm{Cbl}$ phosphorylation and consequent ubiquitylation of the EGFR. Recent reports provide convincing evidence that cortactin is an important regulator during receptor-mediated endocytosis by its interaction with dynamin and actin [16-18]. However, the work by Timpson and colleagues [21] demonstrated that cortactin can interfere directly or indirectly with ligand-induced downregulation of the EGFR. These authors showed that increased expression of cortactin resulted in the inhibition of EGFR degradation and sustained EGFR activity. Together with the observation that the EGFR has already been reported to be activated in carcinomas of the head/neck region due to EGFR DNA amplification [25], these observations imply that constitutive EGFR activity is present in a significant number of these carcinomas. It would be of interest to learn about the role of cortactin expression in regulating the endocytosis of other receptors and cell adhesion molecules.

\section{Competing interests}

The author(s) declare that they have no competing interests.

\section{Acknowledgements}

AGSHvR was supported by grant NKB-RUL 98-1647 of the Dutch Cancer Society and JG by the Research School GUIDE. The authors thank Jeroen Guikema for critical reading of the manuscript.

\section{References}

1. van Rossum AG, Schuuring-Scholtes E, Buuren-van Seggelen V, Kluin PM, Schuuring E: Comparative genome analysis of cortactin and HS1: the significance of the F-actin binding repeat domain. BMC Genomics 2005, 6:15.

2. Weed SA, Parsons JT: Cortactin: coupling membrane dynamics to cortical actin assembly. Oncogene 2001, 20:6418-6434.

3. Daly RJ: Cortactin signalling and dynamic actin networks. Biochem J 2004, 382:13-25.

4. Huang C, Liu J, Haudenschild CC, Zhan X: The role of tyrosine phosphorylation of cortactin in the locomotion of endothelial cells. J Biol Chem 1998, 273:25770-25776.

5. Li Y, Tondravi M, Liu J, Smith E, Haudenschild CC, Kaczmarek M, Zhan $\mathrm{X}$ : Cortactin potentiates bone metastasis of breast cancer cells. Cancer Res 2001, 61:6906-6911.

6. van Rossum AG, De Graaf JH, Schuuring-Scholtes E, Kluin PM, Fan YX, Zhan X, Moolenaar WH, Schuuring E: Alternative splicing of the actin binding domain of human cortactin affects cell migration. J Biol Chem 2003, 278:45672-45679.

7. Bowden ET, Barth M, Thomas D, Glazer RI, Mueller SC: An invasion-related complex of cortactin, paxillin and PKCmu associates with invadopodia at sites of extracellular matrix degradation. Oncogene 1999, 18:4440-4449.

8. Schuuring E, Verhoeven E, Mooi WJ, Michalides RJ: Identification and cloning of two overexpressed genes, U21B31/ PRAD1 and EMS1, within the amplified chromosome 11q13 region in human carcinomas. Oncogene 1992, 7:355-361.

9. Schuuring E, Verhoeven E, Litvinov S, Michalides RJ: The product of the EMS1 gene, amplified and overexpressed in human carcinomas, is homologous to a v-src substrate and is located in cell-substratum contact sites. Mol Cell Biol 1993, 13:28912898.

10. Ormandy CJ, Musgrove EA, Hui R, Daly RJ, Sutherland RL: Cyclin D1, EMS1 and 11q13 amplification in breast cancer. Breast Cancer Res Treat 2003, 78:323-335.

11. Schuuring $E$ : The involvement of the chromosome 11q13 region in human malignancies: cyclin D1 and EMS1 are two new candidate oncogenes - a review. Gene 1995, 159:83-96.

12. Schuuring $E$, Verhoeven $E$, van Tinteren H, Peterse JL, Nunnink B, Thunnissen FB, Devilee P, Cornelisse CJ, van de Vijver MJ, Mooi WJ: Amplification of genes within the chromosome 11q13 
region is indicative of poor prognosis in patients with operable breast cancer. Cancer Res 1992, 52:5229-5234.

13. Lua BL, Low BC: Cortactin phosphorylation as a switch for actin cytoskeletal network and cell dynamics control. FEBS Lett 2005, 579:577-585.

14. Kaksonen M, Peng HB, Rauvala H: Association of cortactin with dynamic actin in lamellipodia and on endosomal vesicles. J Cell Sci 2000, 113:4421-4426.

15. McNiven MA, Kim L, Krueger EW, Orth JD, Cao H, Wong TW: Regulated interactions between dynamin and the actinbinding protein cortactin modulate cell shape. J Cell Biol 2000, 151:187-198.

16. Sauvonnet N, Dujeancourt A, Dautry-Varsat A: Cortactin and dynamin are required for the clathrin-independent endocytosis of $\gamma$ c cytokine receptor. J Cell Bio/ 2005, 168:155-163.

17. Zhu J, Zhou K, Hao JJ, Liu J, Smith N, Zhan X: Regulation of cortactin/dynamin interaction by actin polymerization during the fission of clathrin-coated pits. J Cell Sci 2005, 118:807-817.

18. Merrifield CJ, Perrais D, Zenisek D: Coupling between clathrincoated-pit invagination, cortactin recruitment, and membrane scission observed in live cells. Cell 2005, 121:593-606.

19. Le Roy C, Wrana JL: Clathrin- and non-clathrin-mediated endocytic regulation of cell signalling. Nat Rev Mol Cell Biol 2005, 6:112-126.

20. Marmor MD, Yarden Y: Role of protein ubiquitylation in regulating endocytosis of receptor tyrosine kinases. Oncogene 2004, 23:2057-2070.

21. Timpson P, Lynch DK, Schramek D, Walker F, Daly RJ: Cortactin overexpression inhibits ligand-induced down-regulation of the epidermal growth factor receptor. Cancer Res 2005, 65: 3273-3280.

22. Wu WJ, Tu S, Cerione RA: Activated Cdc42 sequesters c-Cbl and prevents EGF receptor degradation. Cel/ 2003, 114:715725.

23. Hou P, Estrada L, Kinley AW, Parsons JT, Vojtek AB, Gorski JL: Fgd1, the Cdc42 GEF responsible for Faciogenital Dysplasia, directly interacts with cortactin and mAbp1 to modulate cell shape. Hum Mol Genet 2003, 12:1981-1993.

24. Bao J, Gur G, Yarden Y: Src promotes destruction of c-Cbl: implications for oncogenic synergy between Src and growth factor receptors. Proc Natl Acad Sci USA 2003, 100:24382443.

25. Nadal A, Cardesa A: Molecular biology of laryngeal squamous cell carcinoma. Virchows Archiv 2003, 442:1-7. 